\title{
The Role of Regulatory T Cells in Pulmonary Arterial Hypertension
}

\author{
Wen Tian ${ }^{1,2+}$, Shirley Y. Jiang ${ }^{2 \dagger}$, Xinguo Jiang ${ }^{1,2}$, Rasa Tamosiuniene ${ }^{1 \dagger}$, Dongeon $\mathrm{Kim}^{2}$, \\ Torrey Guan ${ }^{1}$, Siham Arsalane ${ }^{1,2}$, Shravani Pasupneti ${ }^{2}$, Norbert F. Voelkel ${ }^{3}$, Qizhi Tang ${ }^{4}$ \\ and Mark R. Nicolls ${ }^{1,2 *}$

\begin{abstract}
${ }^{1}$ Department of Medicine, VA Palo Alto Health Care System, Palo Alto, CA, United States, ${ }^{2}$ Department of Medicine, Stanford University School of Medicine, Stanford, CA, United States, ${ }^{3}$ Department of Pulmonary Medicine, Amsterdam University Medical Centers, Amsterdam, Netherlands, ${ }^{4}$ Department of Surgery, University of California San Francisco, San Francisco, CA, United States
\end{abstract}

Pulmonary arterial hypertension (PAH) is a chronic, incurable condition characterized by pulmonary vascular remodeling, perivascular inflammation, and right heart failure. Regulatory $T$ cells (Tregs) stave off autoimmunity, and there is increasing evidence for their compromised activity in the inflammatory milieu of PAH. Abnormal Treg function is strongly correlated with a predisposition to PAH in animals and patients. Athymic Tregdepleted rats treated with SU5416, an agent causing pulmonary vascular injury, develop $\mathrm{PAH}$, which is prevented by infusing missing $\mathrm{CD}^{+} \mathrm{CD}_{25} 5^{\text {high }} \mathrm{FOXP3}{ }^{+}$Tregs. Abnormal Treg activity may also explain why PAH disproportionately affects women more than men. This mini review focuses on the role of Tregs in PAH with a special view to sexual dimorphism and the future promise of Treg therapy.

Keywords: regulatory $\mathrm{T}$ cell, pulmonary arterial hypertension, sexual dimorphism, right ventricle, estrogen

\section{INTRODUCTION}

The first classification of pulmonary hypertension (PH) was proposed in 1973 and is now defined as an increase in mean pulmonary arterial pressure $(\mathrm{mPAP})>20 \mathrm{mmHg}$ at rest, normal left atrial pressure and pulmonary vascular resistance $>=3$ Wood units (1). This review focuses on PAH which is classified by World Health Organization (WHO) as Group $1 \mathrm{PH}$ (1). PAH includes idiopathic or sporadic cases (IPAH), heritable cases (HPAH, describing patients with a family history or identified germline mutations), and associated forms (attributable to conditions like anorexigens, liver diseases, congenital heart diseases, and connective tissue diseases) (2). Heterozygous germline mutations in gene encoding for bone morphogenetic protein receptor 2 (BMPR2) account for $53-86 \%$ of the familial cases of PAH and $14-35 \%$ of patients with IPAH (3). Although clinical features of HPAH and IPAH are indistinguishable, patients with HPAH have an earlier disease onset with more severe hemodynamics (4). There is a strong sex-associated influence on the development of PAH, with an approximate female to male patients' ratio of 4:1 (5). Although the incidence of $\mathrm{PAH}$ is higher in women, the estimated 5-year survival is less favorable in men (52\% in men compared to $62 \%$ in women) (6). Regardless of the underlying etiology, patients with PAH exhibit similar pathological alterations including remodeling of the pulmonary arterioles driven by proliferation/dysfunction of both pulmonary arterial endothelial cells (PAECs) and smooth muscle cells (PASMCs), in situ thrombosis, increased pulmonary arteriole contractility, and enhanced inflammatory infiltrates (7-9). 
$\mathrm{PAH}$ is a lethal cardiopulmonary condition characterized by pulmonary vascular remodeling and right heart failure (10). Drugs used to treat this disease primarily target pathologic vasoconstriction, but there is an additional rationale for treating immune dysregulation (9). Growing evidence indicates that abnormal Treg activity promotes the development of PAH, and accentuating the activity of these cells has therapeutic potential (9). Tregs play a vital role in maintaining immune homeostasis, fostering tissue regeneration, and limiting vascular injury (11-13). They protect against autoimmunity by dampening inappropriate responses to self-antigen (14). This defensive activity was first identified in mice lacking thymicderived $\mathrm{CD} 4{ }^{+} \mathrm{CD} 25^{\mathrm{hi}}$ Forkhead box P3 (FOXP3) ${ }^{+}$Treg cells and in Treg-depleted animals which develop a constellation of autoimmune conditions including thyroiditis, diabetes, autoimmune gastritis, and inflammatory bowel disease (14, 15). Subsequently, numerous pre-clinical autoimmunity models show that Treg defects are implicated in the development of autoimmune diseases and prevented by the adoptive transfer of Tregs (14). Other types of $\mathrm{CD}^{+}$regulatory $\mathrm{T}$ cells are also discovered including IL-10-producing type 1 regulatory $\mathrm{T}$ cells and TGF- $\beta$ producing-T helper 3 cells $(16,17)$. Here, we only discuss the CD $25^{\text {high }} \mathrm{FOXP}^{+}$Treg population given the broader and indispensable roles of these cells.

PAH-associated conditions exhibit Treg abnormalities (18). Furthermore, Treg dysfunction in PAH affects males and females differently and may arise because of pathogenic gene variants (e.g., mutations in BMPR2 and chronic vascular inflammation (18-20). Our group demonstrated that adoptive transfer of Tregs is effective in preventing pre-clinical PAH (21). Treg infusions restore immune regulation, reduce endothelial injury, impede $\mathrm{PAH}$-mediated vascular remodeling, and prevent right heart failure $(21,22)$. Because Tregs can limit and potentially reverse pulmonary vascular disease, Treg infusions may become a viable treatment for this condition (23). This review explores how genetic and environmental cues may cause Treg abnormalities that exacerbate PAH and discusses how the restoration of Treg function may attenuate this life-threatening disease.

\section{REGULATION OF TREG ONTOGENY, IDENTITY, AND FUNCTION}

Anti-inflammatory $\mathrm{CD} 4{ }^{+} \mathrm{CD} 25^{\text {high }} \mathrm{FOXP}^{+}$Tregs comprise approximately $5 \%$ of $\mathrm{CD}^{+} \mathrm{T}$ cells and develop primarily in the thymus (24-27). Genetic mutations (e.g., FOXP3, RAG1, and $A I R E$ ) (28) impact Treg thymic development and predispose individuals to autoimmune conditions. Continued expression of FOXP3 and sustained FOXP3 signaling are required for Tregs to maintain their lineage-stability and function, and FOXP3 expression is influenced by local tissue microenvironment and sex hormones (26). For example, FOXP3 may be turned on in conventional $\mathrm{T}$ cells (Tconvs, $\mathrm{CD}^{+} \mathrm{FOXP}^{-}$) at peripheral inflammatory sites to promote Treg phenotype (pTregs) (29). High concentrations of interleukin-1 beta (IL-1 $\beta$ ) as well as interleukin-6 (IL-6) may result in decreased FOXP3 and increased interleukin-17 (IL-17) expression in Tregs (exTregs) (30-32). Specifically, proinflammatory IL-6, in conjunction with IL-1 and IL-23, induces the expression of ROR $\gamma \mathrm{t}$ and IL-17 and suppresses FOXP3 thereby causing a genetic reprograming in FOXP3 $^{+}$Treg cells (33). Elevated IL- 6 also promotes the methylation of a conserved $\mathrm{Cp}-\mathrm{G}$-rich island of FOXP3 gene and results in reduced gene transcription (34). Notably, IL-1 $\beta$, IL-6, and IL-17 are elevated in PAH and contribute to Treg instability and pathogenic inflammation $(35,36)$. Additionally, Tregs can specialize into T helper-(Th-) like subsets expressing Th1, Th17, Th2, or Th22 markers and receptors that mimic and suppress Th1, Th17, Th2, or Th22 immunity, respectively (37).

Abnormalities in thymic development and Treg production may be related to the most common genetic mutations in $\mathrm{PAH}$ involving BMPR2 (38). Normal thymus development requires bone morphogenic protein (BMP) signaling (39); thymic epithelial cell maturation requires BMP4 (a BMPR2 ligand) and the activation of FOXN1 transcription factor (40). Consequently, BMPR2 mutations may affect embryonic thymic BMP4 signaling and influence Treg development in early life. It is unknown whether patients with BMPR2 mutations have decreased Tregs or whether the impact of BMPR2 signaling may be more subtle, not affecting Treg numbers globally but rather subset percentages and function. In peripheral lymphoid tissues, BMPR1 $\alpha$ sustains the expression of FOXP3 in pTregs and is required for the maturation and preservation of Treg cell phenotype while inhibiting the differentiation of pro-inflammatory Th1 and Th17 cells (41). Missense mutations of BMPR1 $\beta$ were identified in pediatric IPAH cases (42) suggesting that BMPR1 $\beta$ insufficiency may contribute to the imbalance between Treg and Th1/Th17 populations in PAH. Genetic and environmental factors that govern Treg development and functionality (43) may ultimately play a role in the predisposition to $\mathrm{PAH}$ after vascular injury.

\section{PAH AND TREG ABNORMALITIES}

The immune dysregulation observed in PAH may be attributable to Treg anomalies $(9,18)$. Tregs maintain immune homeostasis, and their deficiency predisposes individuals to autoimmune injury $(13,26,44,45)$. Just as failing Tregs are increasingly recognized in cardiovascular diseases, abnormalities in Treg number and function are also reported in PAH $(18,36,46-$ 49). Inflammatory pathologies are associated with poor clinical outcomes in $\mathrm{PAH}$ and underscore the importance of understanding Treg derangements (9). Extensive pre-clinical evidence from our group and others suggest that abnormal Treg activity may explain autoimmune and inflammatory features noted in PAH (Table 1). Treg numbers are reduced in $\mathrm{PAH}$ lungs but increased in the peripheral circulation, displaying reduced suppressive functionality $(46,47,77,78)$. In addition to the thymic anomalies, defective leptin and adiponectin signaling may also influence Treg function in IPAH patients $(46,79)$.

The heterogeneous vascular lesions of PAH reveal numerous inflammatory cell types in and around the pulmonary vessels, 
TABLE 1 | Clinical and pre-clinical studies show a relationship between Treg abnormalities and PAH-associated conditions.

\begin{tabular}{|c|c|c|c|}
\hline & PAH-associated conditions & PAH prevalence & Treg (T cell) abnormalities \\
\hline \multirow[t]{14}{*}{ Clinical Studies } & Scleroderma & $\approx 10 \%(50)$ & $\downarrow$ Treg function and frequency (51) \\
\hline & Lupus erythematosus & $3 \%-23 \%(52)$ & Altered Treg frequency, $\downarrow$ Treg/Teff(effector $T$ cells) ratio correlate with disease severity (53) \\
\hline & Sjögren's syndrome & $\approx 10 \%(54)$ & Altered Treg frequency; $\downarrow$ Treg/Th17 (55) \\
\hline & Polymyositis & $\approx 10 \%(56)$ & $\downarrow$ Treg frequency and $\downarrow$ Treg/Teff ratio (57) \\
\hline & Antiphospholipid syndrome & Common (58) & $\downarrow$ Treg frequency and $\downarrow$ Treg/Teff ratio (59) \\
\hline & Hashimoto's thyroiditis & case reports (60) & $\downarrow$ Treg/Teff ratio and $\downarrow$ Treg function (61) \\
\hline & HIV infection & $0.5 \%(62)$ & Altered Treg frequency, phenotype, and function (63) \\
\hline & Schistosomiasis & $8 \%-25 \%(64)$ & Altered Treg frequency (65) \\
\hline & Herpesvirus 8 & $\approx 3 \%(66)$ & Altered Treg frequency and function (67) \\
\hline & DiGeorge syndrome & case reports $(68,69)$ & Abnormal thymic Treg development (70) \\
\hline & IPEX syndrome & case report (ATS) (71) & FOXP3 mutations and Treg defects (72) \\
\hline & APS-1 & case report (73) & AIRE mutations and Treg defects (74) \\
\hline & Idiopathic PAH & $\mathrm{n} / \mathrm{a}$ & $\downarrow$ Treg/Th17 (75) \\
\hline & CTD-PAH & $\mathrm{n} / \mathrm{a}$ & $\downarrow$ Treg frequency, $\downarrow$ Treg/Teff ratio and $\downarrow$ Treg function (36) \\
\hline \multirow[t]{2}{*}{ Pre-clinical } & Athymic rats & $100 \%$ after SU5416 & $\downarrow$ Treg causes PAH (w/o hypoxia), Treg reconstitution protects rats from PAH \\
\hline & B6 mice & 100\% after hypoxia & Treg infusion protects mice against PAH (76) \\
\hline
\end{tabular}

suggesting a coordinated immune response $(9,80)$. Treg abnormalities may promote the development and progression of PAH by failing to quell this inflammation following vascular injuries, such as that induced by shear stress, hypoxia, ischemia, or pathogens; the result, a prolonged and destructive period of vascular wound healing $(9,18,20,21,81,82)$. Beyond the regulation of adaptive immunity, Tregs control innate responses following injury. In a Treg-deficient model of PAH, we show that the absence of Tregs contributes to the emergence of destructive macrophage-based immunity culpable in progressive endothelial damage and vascular remodeling (83). Tregs can also control neutrophilic infiltration and preserve endothelial barrier function, possibly relevant to the pathogenesis of PAH $(84,85)$.

\section{MODELING TREG BIOLOGY IN PAH}

Aberrant Treg activity predisposes animals to vascular inflammation and PAH (86). We initially noted a predisposition to severe PAH in animals lacking normal T cells (athymic rats) after exposure to SU5416, a vascular endothelial growth factor 2 (VEGF2) receptor antagonist that causes pulmonary arteriole injury. [Rats robustly model $\mathrm{PAH}$ in a manner not uniformly observed in mice (87)]. Treg-deficient rats exposed to SU5416 demonstrate an accumulation of B cells and macrophages after one week before developing hemodynamically-significant $\mathrm{PAH}$ (21). Restoring missing $\mathrm{CD} 4{ }^{+} \mathrm{CD} 25^{\mathrm{hi}} \mathrm{FOXP} 3^{+}$cells through intravenous infusion limits inflammation, prevents endothelial apoptosis, and ameliorates PAH in this model; these original studies demonstrate a relationship between Treg deficiency and the proclivity for PAH. In SU5416-treated athymic rats, activated macrophages expand and produce leukotriene $\mathrm{B}_{4}\left(\mathrm{LTB}_{4}\right)$ in a lung environment lacking Tregs. This eicosanoid may contribute to pulmonary vascular disease by inducing endothelial cell apoptosis/ transformation, smooth muscle cell proliferation/hypertrophy, and adventitial fibroblast proliferation/migration $(83,88)$. Interestingly, unlike some animal models which observe $\mathrm{PAH}$ more consistently in males, the Treg-deficient rat model shows a profoundly heightened vulnerability to disease in both sexes. In the future, other PAH models (currently in development), with more subtle Treg deficits than the athymic rat, will provide greater opportunities to understand the unique participation of Tregs in pulmonary vascular health and disease.

\section{TREGS AND SEX-RELATED PATHOLOGY IN PAH}

PAH disproportionately affects women more than men (89). Our recent athymic rat study highlights the effect of sex on Treg activities in PAH and suggests the Tregs' dominant role in protecting females against this condition (22). Treg sexual dimorphism is a complex subject. While males have a larger thymus, higher Treg numbers, and more robust Treg immunesuppressive capacity, female hormones enhance Tregs' growth and function $(90,91)$. Because PAH is worse in females in this Treg-deficient model, estrogen (17b-estradiol; $\mathrm{E}_{2}$ ) may be exacerbating immunity in the absence of normal Treg function. $E_{2}$ is a highly pleiotropic hormone for immune function, being both pro-inflammatory and anti-inflammatory under different conditions and with varying types of cells (92). $\mathrm{E}_{2}$ promotes Treg differentiation (93-96) while also enhancing Th2 responses (97) and B cell/macrophage activation (98-100). Treg suppressive activity involves $\mathrm{E}_{2}$-dependent expression of the anti-inflammatory checkpoint molecule Programmed Death-1 (PD-1) (96). Cumulatively, these findings raise the seemingly divergent possibilities that $\mathrm{E}_{2}$ may promote protective Treg function and that $\mathrm{E}_{2}$ can intensify harmful immunity (Figure 1). Because $\mathrm{E}_{2}$ supplementation may be a possible therapeutic strategy in $\mathrm{PAH}$ (84), it is crucial to discern the molecular underpinnings of $\mathrm{E}_{2}$ in $\mathrm{PAH}$ immune injury. Finally, $\mathrm{PAH}$ is prevalent in obese women (101). Tregs are decreased in adipose tissue, a phenomenon that may contribute to persistent low-grade inflammation. Reduced Tregs, expressing adiponectin receptor 1 , in the lungs of obese mice promotes inflammation and a predisposition to PAH (79).

In the absence of Tregs, female $\mathrm{PAH}$ rat lungs exhibit worse hemodynamics, increased macrophage infiltration, a more 


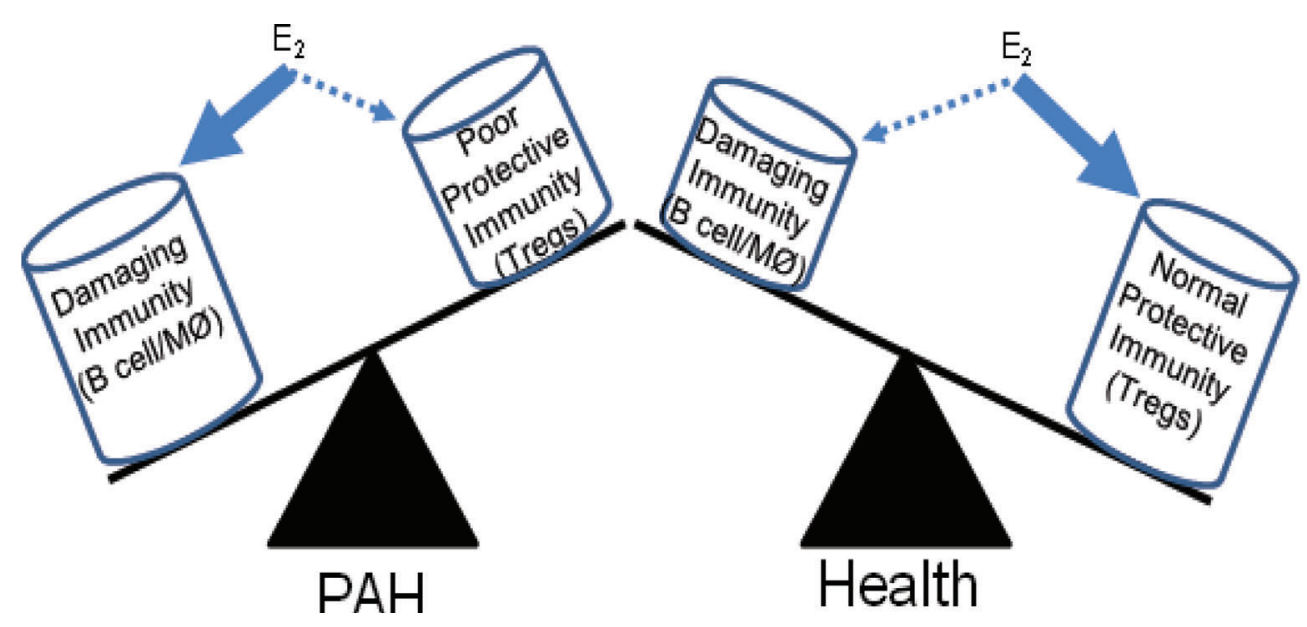

FIGURE 1 | Differential effects of estrogen on immunity in PAH and health. Estrogen $\left(E_{2}\right)$ has complex effects on the immune response. In the absence of normal Treg immunity, $\mathrm{E}_{2}$ may promote damaging $\mathrm{B}$ cell and macrophage responses that induce pulmonary vascular disease and PAH. In health, the positive effects of $\mathrm{E}_{2}$ fostering Treg maturation may dominate.

significant decline in right ventricular (RV) capillary density, and greater RV perivascular and interstitial fibrosis (22). Treg infusion mitigates $\mathrm{PAH}$ and prevents these pathologic changes. Further, prostacyclin $\left(\mathrm{PGI}_{2}\right)$, a potent vasodilator, is decreased in females with PAH and may also contribute to the sex-related differences. Following vascular injury and Treg therapy, $\mathrm{PGI}_{2}$ blood levels increase dramatically. Cyclooxygenase-2 (COX-2) and $\mathrm{PGI}_{2}$ synthase (PTGIS), critical enzymes for $\mathrm{PGI}_{2}$ synthesis, are profoundly upregulated in the lungs of Treg-treated rats. Blocking COX-2, heme oxygenase-1 (HO-1), and Programmed Death Ligand-1 (PD-L1)/PD-1 signaling pathways abrogate Treg protection from PAH (22). Thus, in the absence of regular Treg activity, reduced pulmonary COX-2/PTGIS expression and serum $\mathrm{PGI}_{2}$ levels correlate with worse disease in females. For these reasons, Treg therapy holds promise for PAH patients by helping them restore $\mathrm{PGI}_{2}$ production in their affected lung tissue. Presently, how Tregs promote $\mathrm{PGI}_{2}$ synthesis in the major endothelial cell production sites is unknown.

Pulmonary arteries and RV capillaries remodel in evolving PAH (102). Treg infusion into T cell-deficient rats, treated with SU5416, do not develop pulmonary vascular disease and show increased expression of COX-2, PTGIS, HO-1, and PD-L1 in the smooth muscle cell layer of pulmonary arterioles. The Tregprotected RV, by distinction, demonstrates increased expression of these protective molecules in cardiac intimal cells and myocardium (22). Treg therapy may additionally afford protection in $\mathrm{PAH}$ by upregulating vascular wall BMPR2 (Figure 2). In vitro, Tregs cocultured with cardiac endothelial cells increase the expression of COX-2, PTGIS, HO-1, PD-L1, $\mathrm{PGI}_{2}$, interleukin-10 (IL-10), and estrogen receptors [64-fold for estrogen receptor-alpha (ER- $\alpha$ ) and 22 -fold for ER-beta (ER- $\beta$ )]. Collectively, data from this latter study suggest that Tregs protect against RV injury through augmented biosynthesis of ERs, COX2, HO-1, $\mathrm{PGI}_{2}$, and IL-10 in cardiac vascular endothelial cells; this activity points to a homeostatic endothelial cellTreg interaction.

\section{AN EMERGING RATIONALE FOR TREG THERAPY TO TREAT PAH}

Treg cell therapy holds treatment promise for a variety of conditions $(103,104)$. Purified Tregs from the patient's blood are expanded, conditioned, and infused back into the donor's circulation. Prior studies support the rationale for now developing Treg immunotherapy protocols as a treatment for clinical PAH. This effort will benefit from 1) understanding how infused Tregs home to lungs and draining lymph nodes, 2) discerning how Tregs contribute to vascular repair with more established pulmonary vascular disease, and 3) developing strategies to expand Tregs ex vivo while enhancing their activities and stability. Relatively small numbers of Tregs are needed to prevent $\mathrm{PAH}$ in rats, but their efficacy with these low numbers diminishes if administered after the disease has progressed (21). Existing literature suggests that the infusion of logarithmically increased numbers of Tregs substantially empowers the treatment effect in established disease (105) and could do so for PAH. More than 50 Treg-infusion clinical trials are being tested for autoimmune and inflammatory diseases (103, 104). Co-medication of IL-2, IL-7, or IL-33 promotes Treg survival and proliferation after cell transfer, and strategies that increase FOXP3 expression improve Treg persistence and suppressive function (103). Increasing Treg specificity is promoted through genetic engineering that enhances chimeric antigen receptors (CAR) expression in Tregs (106). However, to date, there are no consistent antigen targets for $\mathrm{PAH}$, and polyclonal Treg infusions may be the most feasible starting approach. 


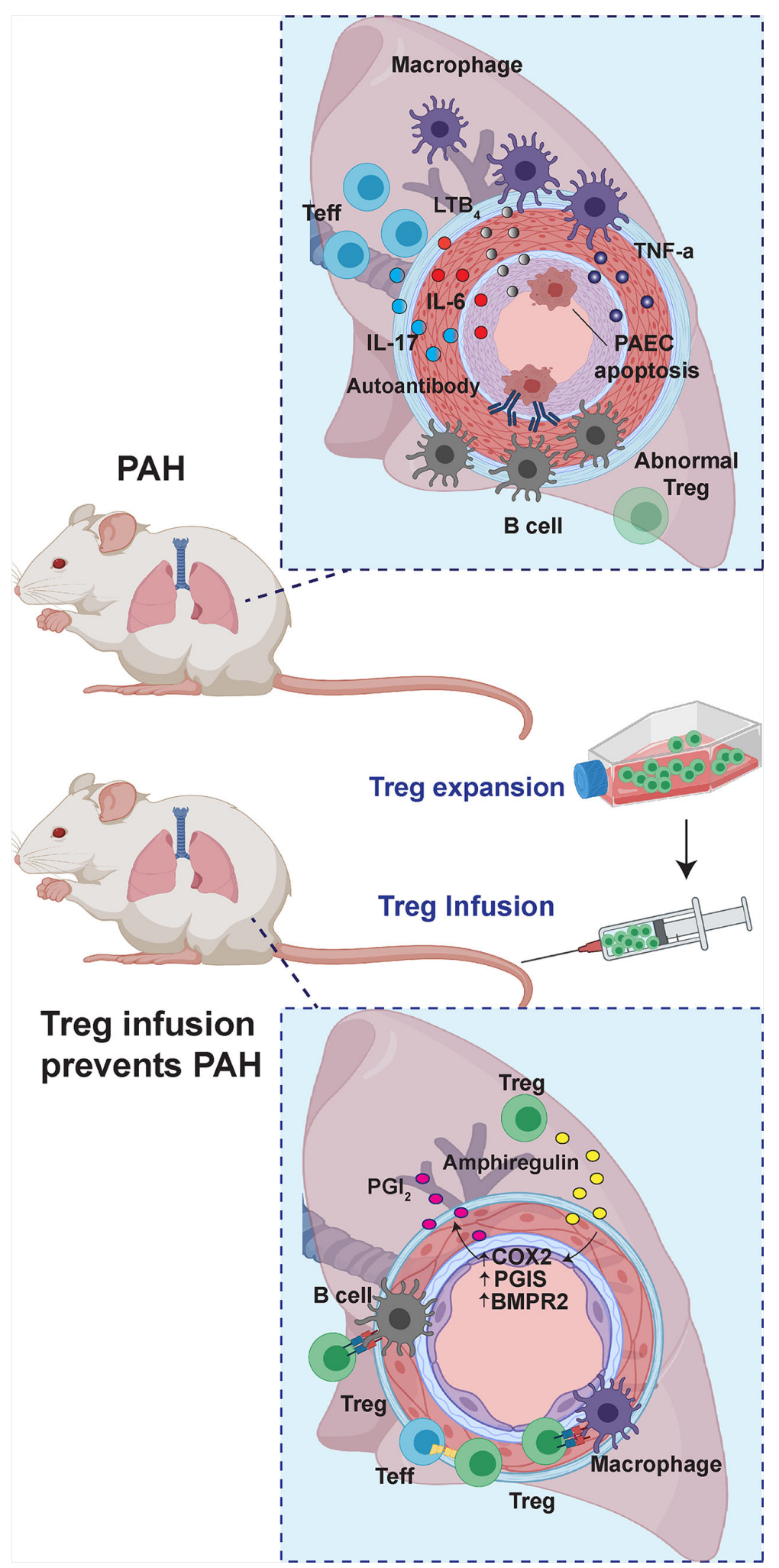

FIGURE 2 | The role of Tregs in PAH. In Treg-deficient rats, vascular injury culminates in enhanced B cell and macrophage-dominated inflammation. With Treg infusion before the induction of vascular injury, $\mathrm{PAH}$ is avoided through upregulation of anti-inflammatory and vasoprotective pathways, which include upregulation of COX2, PGIS, and BMPR2. 


\section{CONCLUSIONS}

Treg dysfunction is a feature of $\mathrm{PAH}$ and contributes to immune dysregulation observed in the disease $(9,107)$. A unique theme of the research presented in this mini-review is that Tregs can directly afford protection to vascular cells, in addition to its better-studied anti-inflammatory effect on other immune cells. In an athymic rat model treated with SU5416 to induce pulmonary vascular injury, Treg infusion also protected right heart function. Sexual differences are present in various PAH manifestations. Consequently, the study of how regulatory immunity differentially impacts men and women with this condition continues to be an area of promising investigation. Combining immune modulators with vasodilators offers potentially better treatment for PAH. Such an approach was recently taken with a randomized multi-center placebocontrolled clinical trial testing B cell depletion with rituximab to treat systemic sclerosis-associated PAH (108); therapy was safe and potentially effective as an adjunct to standard-of-care

\section{REFERENCES}

1. Simonneau G, Montani D, Celermajer DS, Denton CP, Gatzoulis MA, Krowka M, et al. Haemodynamic Definitions and Updated Clinical Classification of Pulmonary Hypertension. Eur Respir J (2019) 53(1): 1801913. doi: 10.1183/13993003.01913-2018

2. Simonneau G, Gatzoulis MA, Adatia I, Celermajer D, Denton C, Ghofrani A, et al. Updated Clinical Classification of Pulmonary Hypertension. J Am Coll Cardiol (2013) 62(25 Suppl):D34-41. doi: 10.1016/j.jacc.2013.10.029

3. Machado RD, Southgate L, Eichstaedt CA, Aldred MA, Austin ED, Best DH, et al. Pulmonary Arterial Hypertension: A Current Perspective on Established and Emerging Molecular Genetic Defects. Hum Mutat (2015) 36(12):1113-27. doi: 10.1002/humu.22904

4. Humbert M, Sitbon O, Chaouat A, Bertocchi M, Habib G, Gressin V, et al. Pulmonary Arterial Hypertension in France: Results From a National Registry. Am J Respir Crit Care Med (2006) 173(9):1023-30. doi: 10.1164/ rccm.200510-1668OC

5. Mair KM, Johansen AK, Wright AF, Wallace E, MacLean MR. Pulmonary Arterial Hypertension: Basis of Sex Differences in Incidence and Treatment Response. Br J Pharmacol (2014) 171(3):567-79. doi: 10.1111/bph.12281

6. Shapiro S, Traiger GL, Turner M, McGoon MD, Wason P, Barst RJ. Sex Differences in the Diagnosis, Treatment, and Outcome of Patients With Pulmonary Arterial Hypertension Enrolled in the Registry to Evaluate Early and Long-Term Pulmonary Arterial Hypertension Disease Management. Chest (2012) 141(2):363-73. doi: 10.1378/chest.10-3114

7. Tuder RM, Archer SL, Dorfmuller P, Erzurum SC, Guignabert C, Michelakis E, et al. Relevant Issues in the Pathology and Pathobiology of Pulmonary Hypertension. J Am Coll Cardiol (2013) 62(25 Suppl):D4-12. doi: 10.1016/ j.jacc. 2013.10.025

8. Humbert M, Guignabert C, Bonnet S, Dorfmuller P, Klinger JR, Nicolls MR, et al. Pathology and Pathobiology of Pulmonary Hypertension: State of the Art and Research Perspectives. Eur Respir J (2019) 53(1):1801887. doi: $10.1183 / 13993003.01887-2018$

9. Rabinovitch M, Guignabert C, Humbert M, Nicolls MR. Inflammation and Immunity in the Pathogenesis of Pulmonary Arterial Hypertension. Circ Res (2014) 115(1):165-75. doi: 10.1161/CIRCRESAHA.113.301141

10. Trammell AW, Shah AJ, Phillips LS, Michael Hart C. Mortality in US Veterans With Pulmonary Hypertension: A Retrospective Analysis of Survival by Subtype and Baseline Factors. Pulm Circ (2019) 9 (1):2045894019825763. doi: 10.1177/2045894019825763 vasodilators. For this reason, as Treg therapy becomes a therapeutic option for a variety of immunological disorders (109, 110), vulnerable PAH patients represent a new and promising target population.

\section{AUTHOR CONTRIBUTIONS}

All authors (WT, SJ, XJ, RT, DK, TG, SA, SP, NV, QT, and MN) contributed to the design, writing and review of this mini review. All authors contributed to the article and approved the submitted version.

\section{FUNDING}

This work was supported by National Institutes of Health grants HL014985, HL122887, and HL138473 to MN.

11. Zaiss DM, Minutti CM, Knipper JA. Immune- and Non-Immune-Mediated Roles of Regulatory T-Cells During Wound Healing. Immunology (2019) 157(3):190-7. doi: 10.1111/imm.13057

12. Arpaia N, Green JA, Moltedo B, Arvey A, Hemmers S, Yuan S, et al. A Distinct Function of Regulatory T Cells in Tissue Protection. Cell (2015) 162 (5):1078-89. doi: 10.1016/j.cell.2015.08.021

13. Vignali DA, Collison LW, Workman CJ. How Regulatory T Cells Work. Nat Rev Immunol (2008) 8(7):523-32. doi: 10.1038/nri2343

14. Sakaguchi S, Yamaguchi T, Nomura T, Ono M. Regulatory T Cells and Immune Tolerance. Cell (2008) 133(5):775-87. doi: 10.1016/j.cell.2008.05.009

15. Ramsdell F, Ziegler SF. FOXP3 and Scurfy: How it All Began. Nat Rev Immunol (2014) 14(5):343-9. doi: 10.1038/nri3650

16. Zhao H, Liao X, Kang Y. Tregs: Where We Are and What Comes Next? Front Immunol (2017) 8:1578. doi: 10.3389/fimmu.2017.01578

17. Shevyrev D, Tereshchenko V. Treg Heterogeneity, Function, and Homeostasis. Front Immunol (2019) 10:3100. doi: 10.3389/fimmu.2019.03100

18. Nicolls MR, Taraseviciene-Stewart L, Rai PR, Badesch DB, Voelkel NF. Autoimmunity and Pulmonary Hypertension: A Perspective. Eur Respir J (2005) 26(6):1110-8. doi: 10.1183/09031936.05.00045705

19. Andruska A, Spiekerkoetter E. Consequences of BMPR2 Deficiency in the Pulmonary Vasculature and Beyond: Contributions to Pulmonary Arterial Hypertension. Int J Mol Sci (2018) 19(9):2499. doi: 10.3390/ijms19092499

20. Tamosiuniene R, Nicolls MR. Regulatory T Cells and Pulmonary Hypertension. Trends Cardiovasc Med (2011) 21(6):166-71. doi: 10.1016/ j.tcm.2012.05.004

21. Tamosiuniene R, Tian W, Dhillon G, Wang L, Sung YK, Gera L, et al. Regulatory T Cells Limit Vascular Endothelial Injury and Prevent Pulmonary Hypertension. Circ Res (2011) 109(8):867-79. doi: 10.1161/ CIRCRESAHA.110.236927

22. Tamosiuniene R, Manouvakhova O, Mesange P, Saito T, Qian J, Sanyal M, et al. Dominant Role for Regulatory T Cells in Protecting Females Against Pulmonary Hypertension. Circ Res (2018) 122(12):1689-702. doi: 10.1161/ CIRCRESAHA.117.312058

23. Meng X, Yang J, Dong M, Zhang K, Tu E, Gao Q, et al. Regulatory T Cells in Cardiovascular Diseases. Nat Rev Cardiol (2016) 13(3):167-79. doi: 10.1038/ nrcardio.2015.169

24. Tsai PT, Lee RA, Wu H. BMP4 Acts Upstream of FGF in Modulating Thymic Stroma and Regulating Thymopoiesis. Blood (2003) 102(12):394753. doi: 10.1182/blood-2003-05-1657

25. Hager-Theodorides AL, Outram SV, Shah DK, Sacedon R, Shrimpton RE, Vicente A, et al. Bone Morphogenetic Protein 2/4 Signaling Regulates Early 
Thymocyte Differentiation. J Immunol (2002) 169(10):5496-504. doi: 10.4049/jimmunol.169.10.5496

26. Benoist C, Mathis D. Treg Cells, Life History, and Diversity. Cold Spring Harb Perspect Biol (2012) 4(9):a007021. doi: 10.1101/cshperspect.a007021

27. Hsieh CS, Lee HM, Lio CW. Selection of Regulatory T Cells in the Thymus. Nat Rev Immunol (2012) 12(3):157-67. doi: 10.1038/nri3155

28. Kalman L, Lindegren ML, Kobrynski L, Vogt R, Hannon H, Howard JT, et al. Mutations in Genes Required for T-Cell Development: IL7R, CD45, IL2RG, JAK3, RAG1, RAG2, ARTEMIS, and ADA and Severe Combined Immunodeficiency: HuGE Review. Genet Med (2004) 6(1):16-26. doi: 10.1097/01.GIM.0000105752.80592.A3

29. Shevach EM, Thornton AM. tTregs, pTregs, and iTregs: Similarities and Differences. Immunol Rev (2014) 259(1):88-102. doi: 10.1111/imr.12160

30. Kimura A, Kishimoto T. IL-6: Regulator of Treg/Th17 Balance. Eur J Immunol (2010) 40(7):1830-5. doi: 10.1002/eji.201040391

31. Hua J, Inomata T, Chen Y, Foulsham W, Stevenson W, Shiang T, et al. Pathological Conversion of Regulatory T Cells Is Associated With Loss of Allotolerance. Sci Rep (2018) 8(1):7059. doi: 10.1038/s41598-018-25384-x

32. Sawant DV, Vignali DA. Once a Treg, Always a Treg? Immunol Rev (2014) 259(1):173-91. doi: 10.1111/imr.12173

33. Yang XO, Nurieva R, Martinez GJ, Kang HS, Chung Y, Pappu BP, et al. Molecular Antagonism and Plasticity of Regulatory and Inflammatory T Cell Programs. Immunity (2008) 29(1):44-56. doi: 10.1016/j.immuni.2008.05.007

34. Lal G, Zhang N, van der Touw W, Ding Y, Ju W, Bottinger EP, et al. Epigenetic Regulation of Foxp3 Expression in Regulatory T Cells by DNA Methylation. J Immunol (2009) 182(1):259-73. doi: 10.4049/jimmunol. 182.1.259

35. Humbert M, Monti G, Brenot F, Sitbon O, Portier A, Grangeot-Keros L, et al. Increased Interleukin-1 and Interleukin-6 Serum Concentrations in Severe Primary Pulmonary Hypertension. Am J Respir Crit Care Med (1995) 151 (5):1628-31. doi: 10.1164/ajrccm.151.5.7735624

36. Gaowa S, Zhou W, Yu L, Zhou X, Liao K, Yang K, et al. Effect of Th17 and Treg Axis Disorder on Outcomes of Pulmonary Arterial Hypertension in Connective Tissue Diseases. Mediators Inflamm (2014) 2014:247372. doi: $10.1155 / 2014 / 247372$

37. Campbell DJ, Koch MA. Phenotypical and Functional Specialization of FOXP3+ Regulatory T Cells. Nat Rev Immunol (2011) 11(2):119-30. doi: $10.1038 /$ nri2916

38. Newman JH, Wheeler L, Lane KB, Loyd E, Gaddipati R, Phillips JA3rd, et al. Mutation in the Gene for Bone Morphogenetic Protein Receptor II as a Cause of Primary Pulmonary Hypertension in a Large Kindred. N Engl J Med (2001) 345(5):319-24. doi: 10.1056/NEJM200108023450502

39. Bleul CC, Boehm T. BMP Signaling Is Required for Normal Thymus Development. J Immunol (2005) 175(8):5213-21. doi: 10.4049/jimmunol. 175.8 .5213

40. Swann JB, Krauth B, Happe C, Boehm T. Cooperative Interaction of BMP Signalling and Foxn1 Gene Dosage Determines the Size of the Functionally Active Thymic Epithelial Compartment. Sci Rep (2017) 7(1):8492. doi: 10.1038/s41598-017-09213-1

41. Browning LM, Miller C, Kuczma M, Pietrzak M, Jing Y, Rempala G, et al. Bone Morphogenic Proteins Are Immunoregulatory Cytokines Controlling FOXP3(+) Treg Cells. Cell Rep (2020) 33(1):108219. doi: 10.1016/j.celrep.2020.108219

42. Chida A, Shintani M, Nakayama T, Furutani Y, Hayama E, Inai K, et al. Missense Mutations of the BMPR1B (ALK6) Gene in Childhood Idiopathic Pulmonary Arterial Hypertension. Circ J (2012) 76(6):1501-8. doi: 10.1253/ circj.CJ-11-1281

43. Mezrich JD, Fechner JH, Zhang X, Johnson BP, Burlingham WJ, Bradfield CA. An Interaction Between Kynurenine and the Aryl Hydrocarbon Receptor can Generate Regulatory T Cells. J Immunol (2010) 185(6):31908. doi: $10.4049 /$ jimmunol.0903670

44. Sakaguchi S. Naturally Arising CD4+ Regulatory T Cells for Immunologic SelfTolerance and Negative Control of Immune Responses. Annu Rev Immunol (2004) 22:531-62. doi: 10.1146/annurev.immunol.21.120601.141122

45. Kim JM, Rasmussen JP, Rudensky AY. Regulatory T Cells Prevent Catastrophic Autoimmunity Throughout the Lifespan of Mice. Nat Immunol (2007) 8(2):191-7. doi: 10.1038/ni1428

46. Huertas A, Phan C, Bordenave J, Tu L, Thuillet R, Le Hiress M, et al. Regulatory T Cell Dysfunction in Idiopathic, Heritable and Connective
Tissue-Associated Pulmonary Arterial Hypertension. Chest (2016) 149 (6):1482-93. doi: 10.1016/j.chest.2016.01.004

47. Sada Y, Dohi Y, Uga S, Higashi A, Kinoshita H, Kihara Y. Non-Suppressive Regulatory T Cell Subset Expansion in Pulmonary Arterial Hypertension. Heart Vessels (2016) 31(8):1319-26. doi: 10.1007/s00380-015-0727-4

48. Ulrich S, Nicolls MR, Taraseviciene L, Speich R, Voelkel N. Increased Regulatory and Decreased CD8+ Cytotoxic T Cells in the Blood of Patients With Idiopathic Pulmonary Arterial Hypertension. Respiration (2008) 75(3):272-80. doi: 10.1159/000111548

49. Jasiewicz M, Moniuszko M, Pawlak D, Knapp M, Rusak M, Kazimierczyk R, et al. Activity of the Kynurenine Pathway and its Interplay With Immunity in Patients With Pulmonary Arterial Hypertension. Heart (2016) 102 (3):230-7. doi: 10.1136/heartjnl-2015-308581

50. Chaisson NF, Hassoun PM. Systemic Sclerosis-Associated Pulmonary Arterial Hypertension. Chest (2013) 144(4):1346-56. doi: 10.1378/chest.12-2396

51. Frantz C, Auffray C, Avouac J, Allanore Y. Regulatory T Cells in Systemic Sclerosis. Front Immunol (2018) 9:2356. doi: 10.3389/fimmu.2018.02356

52. Xia YK, Tu SH, Hu YH, Wang Y, Chen Z, Day HT, et al. Pulmonary Hypertension in Systemic Lupus Erythematosus: A Systematic Review and Analysis of 642 Cases in Chinese Population. Rheumatol Int (2013) 33 (5):1211-7. doi: 10.1007/s00296-012-2525-y

53. Suen JL, Chiang BL. CD4(+)FoxP3(+) Regulatory T-Cells in Human Systemic Lupus Erythematosus. J Formos Med Assoc (2012) 111(9):46570. doi: $10.1016 /$ j.jfma.2012.05.013

54. Sato T, Hatano M, Iwasaki Y, Maki H, Saito A, Minatsuki S, et al. Prevalence of Primary Sjogren's Syndrome in Patients Undergoing Evaluation for Pulmonary Arterial Hypertension. PloS One (2018) 13(5):e0197297. doi: 10.1371/journal.pone.0197297

55. Alunno A, Carubbi F, Bistoni O, Caterbi S, Bartoloni E, Mirabelli G, et al. T Regulatory and T Helper 17 Cells in Primary Sjogren's Syndrome: Facts and Perspectives. Mediators Inflamm (2015) 2015:243723. doi: 10.1155/2015/243723

56. Wang H, Liu T, Cai YY, Luo L, Wang M, Yang M, et al. Pulmonary Hypertension in Polymyositis. Clin Rheumatol (2015) 34(12):2105-12. doi: 10.1007/s10067-015-3095-7

57. Zhang SX, Wang J, Sun HH, Zhang JQ, Liu GY, Luo J, et al. Circulating Regulatory T Cells Were Absolutely Decreased in Dermatomyositis/Polymyositis Patients and Restored by Low-Dose IL-2. Ann Rheum Dis (2019) 14: annrheumdis-2019-216246. doi: 10.1136/annrheumdis-2019-216246

58. Espinosa G, Cervera R, Font J, Asherson RA. The Lung in the Antiphospholipid Syndrome. Ann Rheum Dis (2002) 61(3):195-8. doi: 10.1016/B978-044450987-1/50003-6

59. Dal Ben ER, do Prado CH, Baptista TS, Bauer ME, Staub HL. Decreased Levels of Circulating CD4+CD25+Foxp3+ Regulatory T Cells in Patients With Primary Antiphospholipid Syndrome. J Clin Immunol (2013) 33 (4):876-9. doi: 10.1007/s10875-012-9857-y

60. Ciccone MM, Zito A, Ciampolillo A, Gesualdo M, Zaza P, Rodio M, et al. Pulmonary Hypertension and Hashimoto's Thyroiditis: Does a Relationship Exist? Endocrine (2015) 48(2):621-8. doi: 10.1007/s12020-014-0358-z

61. Glick AB, Wodzinski A, Fu P, Levine AD, Wald DN. Impairment of Regulatory T-Cell Function in Autoimmune Thyroid Disease. Thyroid (2013) 23(7):871-8. doi: 10.1089/thy.2012.0514

62. Almodovar S, Hsue PY, Morelli J, Huang L, Flores SC, Lung HIVS. Pathogenesis of HIV-Associated Pulmonary Hypertension: Potential Role of HIV-1 Nef. Proc Am Thorac Soc (2011) 8(3):308-12. doi: 10.1513/ pats.201006-046WR

63. Lopez-Abente J, Correa-Rocha R, Pion M. Functional Mechanisms of Treg in the Context of HIV Infection and the Janus Face of Immune Suppression. Front Immunol (2016) 7:192. doi: 10.3389/fimmu.2016.00192

64. Papamatheakis DG, Mocumbi AO, Kim NH, Mandel J. SchistosomiasisAssociated Pulmonary Hypertension. Pulm Circ (2014) 4(4):596-611. doi: $10.1086 / 678507$

65. Watanabe K, Mwinzi PN, Black CL, Muok EM, Karanja DM, Secor WE, et al. T Regulatory Cell Levels Decrease in People Infected With Schistosoma Mansoni on Effective Treatment. Am J Trop Med Hyg (2007) 77(4):676-82. doi: $10.4269 /$ ajtmh.2007.77.676

66. Nicastri E, Vizza CD, Carletti F, Cicalini S, Badagliacca R, Poscia R, et al. Human Herpesvirus 8 and Pulmonary Hypertension. Emerg Infect Dis (2005) 11(9):1480-2. doi: 10.3201/eid1109.0408801480 
67. Lepone LM, Rappocciolo G, Piazza PA, Campbell DM, Jenkins FJ, Rinaldo CR. Regulatory T Cell Effect on CD8(+) T Cell Responses to Human Herpesvirus 8 Infection and Development of Kaposi's Sarcoma. AIDS Res Hum Retroviruses (2017) 33(7):668-74. doi: 10.1089/aid.2016.0155

68. Boyarchuk O, Volyanska L, Dmytrash L. Clinical Variability of Chromosome 22q11.2 Deletion Syndrome. Cent Eur J Immunol (2017) 42 (4):412-7. doi: 10.5114/ceji.2017.72818

69. McDonald-McGinn DM, Sullivan KE, Marino B, Philip N, Swillen A, Vorstman JA, et al. 22q11.2 Deletion Syndrome. Nat Rev Dis Primers (2015) 1:15071. doi: 10.1038/nrdp.2015.71

70. Marcovecchio GE, Bortolomai I, Ferrua F, Fontana E, Imberti L, Conforti E, et al. Thymic Epithelium Abnormalities in DiGeorge and Down Syndrome Patients Contribute to Dysregulation in T Cell Development. Front Immunol (2019) 10:447. doi: 10.3389/fimmu.2019.00447

71. Barzaghi F, Passerini L, Bacchetta R. Immune Dysregulation, Polyendocrinopathy, Enteropathy, X-Linked Syndrome: A Paradigm of Immunodeficiency With Autoimmunity. Front Immunol (2012) 3:211. doi: 10.3389/fimmu.2012.00211

72. Le Bras S, Geha RS. IPEX and the Role of Foxp3 in the Development and Function of Human Tregs. J Clin Invest (2006) 116(6):1473-5. doi: 10.1172/JCI28880

73. Korniszewski L, Kurzyna M, Stolarski B, Torbicki A, Smerdel A, Ploski R. Fatal Primary Pulmonary Hypertension in a 30 - $\mathrm{Yr}$-Old Female With APECED Syndrome. Eur Respir J (2003) 22(4):709-11. doi: 10.1183/ 09031936.03.00018203

74. Husebye ES, Anderson MS, Kampe O. Autoimmune Polyendocrine Syndromes. N Engl J Med (2018) 378(12):1132-41. doi: 10.1056/NEJMra1713301

75. Hautefort A, Girerd B, Montani D, Cohen-Kaminsky S, Price L, Lambrecht $\mathrm{BN}$, et al. T-Helper 17 Cell Polarization in Pulmonary Arterial Hypertension. Chest (2015) 147(6):1610-20. doi: 10.1378/chest.14-1678

76. Chu Y, Xiangli X, Xiao W. Regulatory T Cells Protect Against HypoxiaInduced Pulmonary Arterial Hypertension in Mice. Mol Med Rep (2015) 11 (4):3181-7. doi: 10.3892/mmr.2014.3106

77. Austin ED, Rock MT, Mosse CA, Vnencak-Jones CL, Yoder SM, Robbins IM, et al. T Lymphocyte Subset Abnormalities in the Blood and Lung in Pulmonary Arterial Hypertension. Respir Med (2010) 104(3):454-62. doi: 10.1016/j.rmed.2009.10.004

78. Savai R, Pullamsetti SS, Kolbe J, Bieniek E, Voswinckel R, Fink L, et al. Immune and Inflammatory Cell Involvement in the Pathology of Idiopathic Pulmonary Arterial Hypertension. Am J Respir Crit Care Med (2012) 186 (9):897-908. doi: 10.1164/rccm.201202-0335OC

79. Ramos-Ramirez P, Malmhall C, Johansson K, Adner M, Lotvall J, Bossios A. Lung Regulatory T Cells Express Adiponectin Receptor 1: Modulation by Obesity and Airway Allergic Inflammation. Int J Mol Sci (2020) 21(23):8990. doi: $10.3390 /$ ijms 21238990

80. Dib H, Tamby MC, Bussone G, Regent A, Berezne A, Lafine C, et al. Targets of Anti-Endothelial Cell Antibodies in Pulmonary Hypertension and Scleroderma. Eur Respir J (2011) 39(6):1405-14. doi: 10.1183/09031936.00181410

81. Clever D, Roychoudhuri R, Constantinides MG, Askenase MH, Sukumar M, Klebanoff CA, et al. Oxygen Sensing by $\mathrm{T}$ Cells Establishes an Immunologically Tolerant Metastatic Niche. Cell (2016) 166(5):1117-31 e14. doi: 10.1016/j.cell.2016.07.032

82. Zhong Q, Jenkins J, Moldobaeva A, D'Alessio F, Wagner EM. Effector T Cells and Ischemia-Induced Systemic Angiogenesis in the Lung. Am J Respir Cell Mol Biol (2016) 54(3):394-401. doi: 10.1165/rcmb.2015-0087OC

83. Tian W, Jiang X, Tamosiuniene R, Sung YK, Qian J, Dhillon G, et al. Blocking Macrophage Leukotriene B4 Prevents Endothelial Injury and Reverses Pulmonary Hypertension. Sci Transl Med (2013) 5(200):200ra117. doi: 10.1126/scitranslmed.3006674

84. Taylor S, Dirir O, Zamanian RT, Rabinovitch M, Thompson AAR. The Role of Neutrophils and Neutrophil Elastase in Pulmonary Arterial Hypertension. Front Med (Lausanne) (2018) 5:217. doi: 10.3389/fmed.2018.00217

85. Ring S, Inaba Y, Da M, Bopp T, Grabbe S, Enk A, et al. Regulatory T Cells Prevent Neutrophilic Infiltration of Skin During Contact Hypersensitivity Reactions by Strengthening the Endothelial Barrier. J Invest Dermatol (2021) 141(8):2006-2017. doi: 10.1016/j.jid.2021.01.027

86. Qiu H, He Y, Ouyang F, Jiang P, Guo S, Guo Y. The Role of Regulatory T Cells in Pulmonary Arterial Hypertension. J Am Heart Assoc (2019) 8(23): e014201. doi: 10.1161/JAHA.119.014201
87. Gomez-Arroyo J, Saleem SJ, Mizuno S, Syed AA, Bogaard HJ, Abbate A, et al. A Brief Overview of Mouse Models of Pulmonary Arterial Hypertension: Problems and Prospects. Am J Physiol Lung Cell Mol Physiol (2012) 302(10):L977-91. doi: 10.1152/ajplung.00362.2011

88. Qian J, Tian W, Jiang X, Tamosiuniene R, Sung YK, Shuffle EM, et al. Leukotriene B4 Activates Pulmonary Artery Adventitial Fibroblasts in Pulmonary Hypertension. Hypertension (2015) 66(6):1227-39. doi: 10.1161/HYPERTENSIONAHA.115.06370

89. Lahm T, Tuder RM, Petrache I. Progress in Solving the Sex Hormone Paradox in Pulmonary Hypertension. Am J Physiol Lung Cell Mol Physiol (2014) 307(1):L7-26. doi: 10.1152/ajplung.00337.2013

90. Klein SL, Flanagan KL. Sex Differences in Immune Responses. Nat Rev Immunol (2016) 16(10):626-38. doi: 10.1038/nri.2016.90

91. Goodman WA, Bedoyan SM, Havran HL, Richardson B, Cameron MJ, Pizarro TT. Impaired Estrogen Signaling Underlies Regulatory T Cell Lossof-Function in the Chronically Inflamed Intestine. Proc Natl Acad Sci U S A (2020) 117(29):17166-76. doi: 10.1073/pnas.2002266117

92. Straub RH. The Complex Role of Estrogens in Inflammation. Endocr Rev (2007) 28(5):521-74. doi: 10.1210/er.2007-0001

93. Polanczyk MJ, Carson BD, Subramanian S, Afentoulis M, Vandenbark AA, Ziegler SF, et al. Cutting Edge: Estrogen Drives Expansion of the CD4+CD25 + Regulatory T Cell Compartment. J Immunol (2004) 173(4):2227-30. doi: 10.4049/jimmunol.173.4.2227

94. Polanczyk MJ, Hopke C, Huan J, Vandenbark AA, Offner H. Enhanced FoxP3 Expression and Treg Cell Function in Pregnant and Estrogen-Treated Mice. J Neuroimmunol (2005) 170(1-2):85-92. doi: 10.1016/j.jneuroim.2005.08.023

95. Polanczyk MJ, Hopke C, Vandenbark AA, Offner H. Estrogen-Mediated Immunomodulation Involves Reduced Activation of Effector $\mathrm{T}$ Cells, Potentiation of Treg Cells, and Enhanced Expression of the PD-1 Costimulatory Pathway. J Neurosci Res (2006) 84(2):370-8. doi: 10.1002/jnr.20881

96. Polanczyk MJ, Hopke C, Vandenbark AA, Offner H. Treg Suppressive Activity Involves Estrogen-Dependent Expression of Programmed Death-1 (PD-1). Int Immunol (2007) 19(3):337-43. doi: 10.1093/intimm/dxl151

97. Pernis AB. Estrogen and CD4+ T Cells. Curr Opin Rheumatol (2007) 19 (5):414-20. doi: 10.1097/BOR.0b013e328277ef2a

98. Beagley KW, Gockel CM. Regulation of Innate and Adaptive Immunity by the Female Sex Hormones Oestradiol and Progesterone. FEMS Immunol Med Microbiol (2003) 38(1):13-22. doi: 10.1016/S0928-8244(03)00202-5

99. Cohen-Solal JF, Jeganathan V, Grimaldi CM, Peeva E, Diamond B. Sex Hormones and SLE: Influencing the Fate of Autoreactive B Cells. Curr Top Microbiol Immunol (2006) 305:67-88. doi: 10.1007/3-540-29714-6_4

100. Grimaldi CM, Cleary J, Dagtas AS, Moussai D, Diamond B. Estrogen Alters Thresholds for B Cell Apoptosis and Activation. J Clin Invest (2002) 109 (12):1625-33. doi: 10.1172/JCI0214873

101. Sweeney L, Voelkel NF. Estrogen Exposure, Obesity and Thyroid Disease in Women With Severe Pulmonary Hypertension. Eur J Med Res (2009) 14 (10):433-42. doi: 10.1186/2047-783x-14-10-433

102. Voelkel NF, Gomez-Arroyo J, Abbate A, Bogaard HJ, Nicolls MR. Pathobiology of Pulmonary Arterial Hypertension and Right Ventricular Failure. Eur Respir J (2012) 40(6):1555-65. doi: 10.1183/09031936.00046612

103. Ferreira LMR, Muller YD, Bluestone JA, Tang Q. Next-Generation Regulatory T Cell Therapy. Nat Rev Drug Discov (2019) 18(10):749-69. doi: 10.1038/s41573-019-0041-4

104. Esensten JH, Muller YD, Bluestone JA, Tang Q. Regulatory T-Cell Therapy for Autoimmune and Autoinflammatory Diseases: The Next Frontier. $J$ Allergy Clin Immunol (2018) 142(6):1710-8. doi: 10.1016/j.jaci.2018.10.015

105. Nguyen VH, Zeiser R, Dasilva DL, Chang DS, Beilhack A, Contag CH, et al. In Vivo Dynamics of Regulatory T-Cell Trafficking and Survival Predict Effective Strategies to Control Graft-Versus-Host Disease Following Allogeneic Transplantation. Blood (2007) 109(6):2649-56. doi: 10.1182/blood-2006-08-044529

106. Mohseni YR, Tung SL, Dudreuilh C, Lechler RI, Fruhwirth GO, Lombardi G. The Future of Regulatory T Cell Therapy: Promises and Challenges of Implementing CAR Technology. Front Immunol (2020) 11:1608. doi: 10.3389/fimmu. 2020.01608

107. Nicolls MR, Voelkel NF. The Roles of Immunity in the Prevention and Evolution of Pulmonary Arterial Hypertension. Am J Respir Crit Care Med (2017) 195(10):1292-9. doi: 10.1164/rccm.201608-1630PP

108. Zamanian RT, Badesch D, Chung L, Domsic RT, Medsger T, Pinckney A, et al. Safety and Efficacy of B-Cell Depletion With Rituximab for the 
Treatment of Systemic Sclerosis-Associated Pulmonary Arterial Hypertension: A Multicenter, Double-Blind, Randomized, PlaceboControlled Trial. Am J Respir Crit Care Med (2021) 204(2):209-221. doi: $10.1164 / \mathrm{rccm} .202009-3481 \mathrm{OC}$

109. Tang Q, Bluestone JA. Regulatory T-Cell Therapy in Transplantation: Moving to the Clinic. Cold Spring Harb Perspect Med (2013) 3(11): a015552. doi: 10.1101/cshperspect.a015552

110. Singer BD, King LS, D'Alessio FR. Regulatory T Cells as Immunotherapy. Front Immunol (2014) 5:46. doi: 10.3389/fimmu.2014.00046

Conflict of Interest: The authors declare that the research was conducted in the absence of any commercial or financial relationships that could be construed as a potential conflict of interest.
Publisher's Note: All claims expressed in this article are solely those of the authors and do not necessarily represent those of their affiliated organizations, or those of the publisher, the editors and the reviewers. Any product that may be evaluated in this article, or claim that may be made by its manufacturer, is not guaranteed or endorsed by the publisher.

Copyright (C) 2021 Tian, Jiang, Jiang, Tamosiuniene, Kim, Guan, Arsalane, Pasupneti, Voelkel, Tang and Nicolls. This is an open-access article distributed under the terms of the Creative Commons Attribution License (CC BY). The use, distribution or reproduction in other forums is permitted, provided the original author(s) and the copyright owner(s) are credited and that the original publication in this journal is cited, in accordance with accepted academic practice. No use, distribution or reproduction is permitted which does not comply with these terms. 